Article

\title{
Synergetic Effects during Co-Pyrolysis of Sheep Manure and Recycled Polyethylene Terephthalate
}

\author{
Zuhal Akyürek \\ Department of Energy Systems Engineering, Faculty of Engineering and Architecture, Burdur Mehmet Akif \\ Ersoy University, Burdur 15030, Turkey; drzuhalakyurek@gmail.com
}

Citation: Akyürek, Z. Synergetic Effects during Co-Pyrolysis of Sheep Manure and Recycled Polyethylene Terephthalate. Polymers 2021, 13, 2363. https://doi.org/10.3390/ polym 13142363

\section{Academic Editors: Sheila}

Devasahayam, Raman Singh and Vladimir Strezov

Received: 7 July 2021

Accepted: 16 July 2021

Published: 19 July 2021

Publisher's Note: MDPI stays neutral with regard to jurisdictional claims in published maps and institutional affiliations.

Copyright: (C) 2021 by the author. Licensee MDPI, Basel, Switzerland. This article is an open access article distributed under the terms and conditions of the Creative Commons Attribution (CC BY) license (https:/ / creativecommons.org/licenses/by/ $4.0 /)$.

\begin{abstract}
Continuous growth in energy demand and plastic waste production are two global emerging issues that require development of clean technologies for energy recovery and solid waste disposal. Co-pyrolysis is an effective thermochemical route for upgrading waste materials to produce energy and value added products. In this study, co-pyrolysis of sheep manure (SM) and recycled polyethylene terephthalate (PET) was studied for the first time in a thermogravimetric analyzer (TGA) in the temperature range of $25-1000{ }^{\circ} \mathrm{C}$ with heating rates of $10-30-50{ }^{\circ} \mathrm{C} \mathrm{min}-1$ under a nitrogen atmosphere. The synergetic effects of co-pyrolysis of two different waste feedstock were investigated. The kinetic parameters are determined using the Flynn-Wall-Ozawa (FWO) model. The results revealed that the mean values of apparent activation energy for the decomposition of sheep manure into a recycled polyethylene terephthalate blend are determined to be $86.27,241.53$, and $234.51 \mathrm{~kJ} / \mathrm{mol}$, respectively. The results of the kinetic study on co-pyrolysis of sheep manure with plastics suggested that co-pyrolysis is a viable technique to produce green energy.
\end{abstract}

Keywords: co-pyrolysis; synergy; kinetics; plastic waste; animal manure

\section{Introduction}

Depletion of fossil fuel reserves (petroleum, coal, natural gas) together with the environmental concerns of fossil fuel combustion have diverted attention towards renewable energy sources worldwide. According to the International Energy Agency (IEA), Global $\mathrm{CO}_{2}$ emissions from fuel combustion reached $33.5 \mathrm{GtCO}_{2}$ carbon dioxide emissions, and $40 \%$ of the emissions stem from electricity generation, driven by factors such as electricity output, generation efficiency, and carbon intensity of fossil fuel generation [1]. Biomass energy is one of the emerging alternatives for reduction of $\mathrm{CO}_{2}$ emissions and diversification of energy sources. Biomass can contribute to sustainable development while reducing climate change impacts on industry [2]. Biomass is the fourth largest energy system after coal, oil and gas with a share of $14 \%$ in global energy consumption. Electricity generation from bioenergy is predicted to show an annual increase of $6 \%$ through to 2030 in the Sustainable Development Scenario (SDS) [3].

Solid waste generation increases gradually due to population growth, developments in industry and enhanced living standards. Carbon neutral energy sources such as biomass can be utilized to address the issues of energy production and waste management [4]. Biomass is an abundant source that can be converted into energy. Organic materials such as agricultural crops, organic wastes, forest residues and livestock manure can be used as biomass feedstock. Livestock manure is a challenging biomass that needs to be carefully managed in order to minimize the greenhouse gas emissions $\left(\mathrm{CH}_{4}, \mathrm{~N}_{2} \mathrm{O}\right)$, adverse health effects and pollution of aquifers and surface waters [5,6].

Plastic waste is one of the fastest-growing environmental pollutant materials. Plastic production has increased in the last decades, due to the applications of several industries such as packaging, construction, buildings, electronics, textiles, machinery etc. Degradation of plastics changes from weeks to several years. Global plastics production almost reached 
370 million tons, and in Europe plastics production almost reached 58 million tons [7]. The continuous rise in plastics consumption has led to adverse effects on the environment $[8,9]$. Plastic wastes can be managed through recycling or energy recovery methods [10]. Recycling is a possible way of plastic waste disposal. Nevertheless, recycling processes are generally costly, energy intensive, and the quality of the product is low [11]. The plastics have high calorific value because they are produced from petrochemical sources. Plastic waste generally ends up in landfills. Lost energy in landfills is estimated to be 2.8 quads of energy equivalence [4]. Hence, energy production from plastic waste has gained interest, to minimize the waste and energy loss.

Thermochemical conversion methods can be used for waste treatment in order to eliminate plastic waste. Combustion or incineration of plastic materials may generate harmful emissions to the atmosphere. Pyrolysis, on the other hand, is one of the viable thermal treatment routes for waste minimization and energy recovery from solid waste $[12,13]$. Pyrolysis is a precursor for combustion and gasification processes [14]. During pyrolysis, long chain polymers degrade into smaller molecules in oxygen free environments [15]. The major products that are produced during pyrolysis are bio-oil, synthetic gas, and biochar products. Depending on the heating rate and residence time, pyrolysis can be classified into three categories: slow, fast and flash pyrolysis [16]. Slow pyrolysis is generally applied for biochar production. Thermal decomposition of biomass takes place under low heating rates and sufficient residence time for re-polymerization reactions in order to increase the yield of solid product termed as biochar. Biochar is to be used in various applications such as soil amendment, energy production and control of pollutants [17]. Fast and flash pyrolysis generally produces higher amounts of bio-oil [18]. Biomass pyrolysis is a complex process due to varying reaction mechanisms and reaction rates during decomposition of the different biomass components [19]. Pyrolysis efficiency also depends on the operational conditions and reactor design.

Co-pyrolysis is considered to be an easy and safe process for producing high quality fuels [20]. Biomass/plastics co-pyrolysis is as an effective upgrading method that will not only increase the bio-oil yield but also reduce activation energy compared to individual pyrolysis of raw materials [4]. In the study of Zhang et al. [21], thermal decomposition behavior and kinetics of sawdust and plastic waste co-pyrolysis was investigated by using a thermogravimetric analyzer (TGA), and synergistic interactions were detected during co-pyrolysis. Aboulkas et al. [22] carried out olive residue/plastic waste (high and low density polyethylene, polypropylene and polystyrene) co-pyrolysis experiments in TGA. The results indicated significant synergy interactions at the high temperature region. Alam et al. [23] studied co-pyrolysis of bamboo sawdust and linear low-density polyethylene in TGA. Synergistic interactions were more obvious with the blend $25 \mathrm{wt} \%$ bamboo sawdust. Uzoejinwa et al. [24] reviewed the benefits of the co-pyrolysis process, product yields, mechanisms of biomass with plastics, and synergetic effects during co-pyrolysis. They stated that co-pyrolysis could serve as a solid waste management method for reducing waste inventory and reducing the dependency on fossil fuels.

Plastics and animal manure can cause detrimental effects on the environment and threaten public health. Their utilization in co-pyrolysis processes provides the reduction of pollutants, on one hand, and recovers green energy, on the other. Kinetics of conversion is essential to understanding the pyrolysis of biomass and plastic materials. In this study, co-pyrolysis characteristics of sheep manure and polyethylene terephthalate (PET) were investigated and identified from thermogravimetric analysis coupled with kinetic study.

\section{Materials and Methods}

\subsection{Raw Materials}

Livestock farming has a high contribution to the economy in Turkey. The availability of animal manure signifies its potential for energy production. In this study, sheep manure (SM) (Figure 1a) and Polyethylene terephthalate (PET) (Figure 1b) were used as raw materials. Manure was obtained from the Koç Family Farm in Ağlasun, Burdur, Turkey. 
The sample was dried in oven at $80^{\circ} \mathrm{C}$ overnight, and then a piece was cut out which was $0.5-1 \mathrm{~mm}$ size. Polyethylene terephthalate (PET) samples were reduced into the similar size range with the sheep manure (SM).

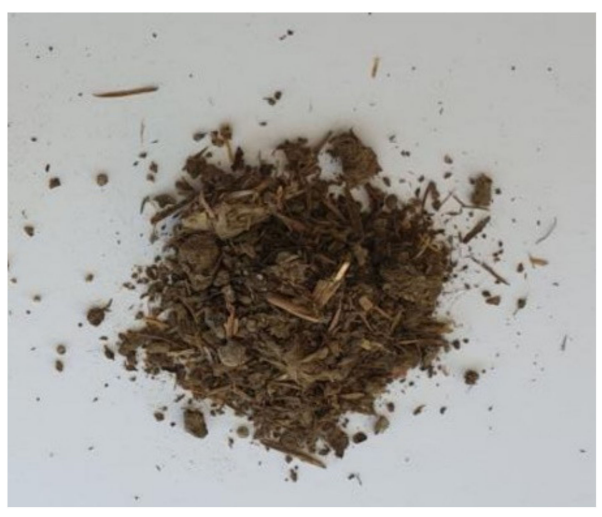

(a)

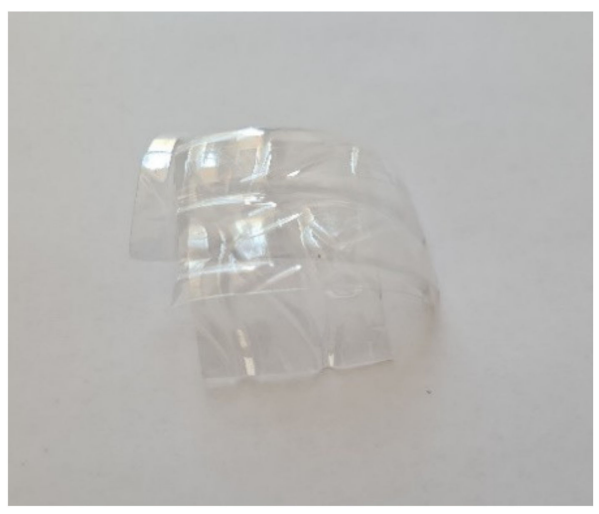

(b)

Figure 1. Photograph of raw materials (a) SM, (b) PET.

In Table 1, the proximate and elemental analyses of the samples are shown. Moisture, volatile matter, and ash contents of the feedstock were determined by ASTM D3173, ASTM D 3175, ASTM D 3174, respectively. The major elements (C, H, N, S) were detected by the LECO CHNS-932 elemental analyzer, and the content of $\mathrm{O}$ was calculated by the difference. The calorific value of the samples was determined in the LECO AC-350 Bomb Calorimeter.

Table 1. Proximate and ultimate analyses of samples.

\begin{tabular}{ccc}
\hline & Proximate Analysis (As Received Basis) & \\
& SM & PET \\
\hline Moisture, $\%$ & 19.42 & 0.65 \\
Volatile Matter, \% & 38.78 & 86.12 \\
Fixed Carbon, \% & 12.88 & 13.19 \\
Ash, \% & 28.92 & 0.04 \\
\hline & Ultimate Analysis (Dry Basis) \\
C, \% & 22.50 & 63.5 \\
N, \% & 3.48 & 4.7 \\
S, \% & 3.09 & 0.05 \\
O, \% (by difference) & 0.50 & 0.03 \\
LHV (kJ/kg) & 32.73 & 31.68 \\
\hline
\end{tabular}

\subsection{Thermogravimetric Analysis}

Thermogravimetric (TG) and derivative thermogravimetric (DTG) analysis experiments of the sheep manure and recycled polyethylene terephthalate were carried out using a TG analyzer (Seiko SII TG/DTA 7200) under a nitrogen flow of $100 \mathrm{~mL} / \mathrm{min}$, heated from room temperature up to $900-1000{ }^{\circ} \mathrm{C}$. The experiments were carried out at three different heating rates $\left(10,30\right.$ and $\left.50^{\circ} \mathrm{C} / \mathrm{min}\right)$. The sample weight was kept at about $10 \mathrm{mg}$.

The evolution with temperature of weight loss (TG) and the weight loss rate (DTG) were obtained for pyrolysis. The weight loss rate was calculated as [25]:

$$
\left(\frac{d W}{d t}\right)=-\frac{1}{w_{0}}\left(\frac{d m}{d t}\right)
$$

where $W_{0}$ is the initial sample mass. 
The synergistic effects during co-pyrolysis of (50:50 wt\%) SM and PET blend was determined by calculating the difference of weight loss $(\Delta W)$ on the basis of each material during pyrolysis [26];

$$
\Delta W=W_{\text {Blend }}-\left(\frac{W_{1}+W_{2}}{2}\right)
$$

\subsection{Kinetic Analysis}

In order to estimate the kinetic parameters of pyrolysis, the isoconversional methods are commonly applied. In this study, the Flynn-Wall-Ozawa (FWO) method was used to estimate the apparent activation energy of SM, PET and their blend (50:50 $\mathrm{wt} \%)$. Pyrolysis kinetics of biomass can be expressed according to the Arrhenius relation, $k(T)$ as;

$$
k(T)=A \exp \left(\frac{-E}{R T}\right)
$$

where $T(K)$ is the absolute temperature, $k(T)$ is the reactivity (the rate constant) depending on the temperature, $A(\mathrm{~s}-1)$ is the pre-exponential factor, $E(\mathrm{~J} / \mathrm{mol})$ is the activation energy and $\mathrm{R}$ is the universal gas constant $(8.314 \mathrm{KJ} / \mathrm{mol} \mathrm{K})$.

The kinetics of heterogeneous solid-state thermal degradation is dominated by the fundamental equation [22];

$$
\begin{gathered}
\frac{d \alpha}{d t}=k(T) f(\alpha) \\
\frac{d \alpha}{d t}=A \exp \left(\frac{-E_{A}}{R T}\right) f(\alpha)
\end{gathered}
$$

where $t$ is the time, and $f(\alpha)$ is the reaction function depending on the conversion rate $\alpha$ in relation to the reaction model, at the conversion degree $\alpha$.

The conversion for pyrolysis is described as;

$$
\alpha=\frac{W_{0}-W_{t}}{W_{0}-W_{f}}
$$

where $W_{0}$ and $W_{f}$ are the initial and final weight of the sample, respectively. $W_{t}$ is the weight of the sample at temperature $T$.

Heating rate $\beta(\mathrm{K} / \mathrm{s})$ is defined as;

$$
\beta=\frac{d T}{d t}
$$

Equation (2) can be transformed into;

$$
\frac{d \alpha}{d T}=\frac{A}{\beta} \exp \left(\frac{-E_{A}}{R T}\right) f
$$

The integrated form of $f(\alpha)$ is generally expressed as;

$$
G(\alpha)=\int_{0}^{\alpha} \frac{d(\alpha)}{f(\alpha)}=\frac{A}{\beta} \int_{T_{0}}^{T} \exp \left(\frac{-E}{R T}\right) d T
$$

\subsubsection{The Flynn-Wall-Ozawa (FWO) Method}

Flynn-Wall-Ozawa (FWO) is an integration method, which provides a linear correlation for a given value of conversion at different heating rates [27,28];

$$
\operatorname{In} \beta=\operatorname{In} \frac{A E_{a}}{\operatorname{Rg}(\alpha)}-5.331-1.052 \frac{E_{a}}{R T}
$$


The apparent activation energy can be calculated from the plot of $\operatorname{In} \beta$ vs. $1 / T$ for a given value of conversion, where the slope is equal to $-1.052 E_{a} / R$.

\subsubsection{Thermodynamic Parameters}

The pre-exponential factors $(A)$ and other thermodynamic parameters such as Enthalpy $(\Delta H)$, Gibbs free energy $(\Delta G)$, and entropy $(\Delta S)$ were calculated by Equations (11)-(14)

$$
\begin{gathered}
A=\beta \cdot E_{a} \cdot \exp \left(\frac{E_{a}}{R \cdot T_{\max }}\right) \cdot \frac{1}{R \cdot T_{\max }^{2}} \\
\Delta H=E_{a}-R T \\
\Delta G=E_{a}+R \cdot T_{\max } \cdot \operatorname{In}\left(\frac{K_{b} \cdot T_{\max }}{h \cdot A}\right) \\
\Delta S=\frac{\Delta H-\Delta G}{T_{\max }}
\end{gathered}
$$

where $T_{\max }$ is the peak temperature, $\mathrm{KB}$ is the Boltzmann constant $\left(1.381 \times 10^{-23} \mathrm{~J} / \mathrm{K}\right)$ and $\mathrm{h}$ is the Plank constant $\left(6.626 \times 10^{-34} \mathrm{~J} . \mathrm{s}\right)$.

\section{Results and Discussion}

\subsection{Pyrolysis and Co-Pyrolysis of SM and PET}

Thermogravimetric analysis is a useful method in order to explain the thermal decomposition of the fuel and reaction mechanisms, which occurred during pyrolysis. The $T G$ curves shows the weight change with respect to temperature change during thermal degradation, and the DTG curves show the corresponding rates of mass loss of the TG curves. In Figure 2, pyrolysis behavior of the sheep manure and polyethylene terephthalate were presented with the mass loss (TG) and derivative mass loss (DTG) curves under different heating conditions.

Pyrolysis behavior and characteristic temperatures such as initial decomposition temperature $\left(T_{i n}\right)$, peak temperature $\left(T_{\max }\right)$, and final temperature $\left(T_{f}\right)$ were obtained from TGA-DTG profiles, as listed in Table 2.

Table 2. Characteristic temperatures of pyrolysis.

\begin{tabular}{cccccccccc}
\hline & \multicolumn{3}{c}{ SM } & & \multicolumn{3}{c}{ PET } & \multicolumn{3}{c}{ Blend } \\
\hline$\beta\left({ }^{\circ} \mathrm{C} / \mathrm{min}\right)$ & 10 & 30 & 50 & 10 & 30 & 50 & 10 & 30 & 50 \\
$T_{i}\left({ }^{\circ} \mathrm{C}\right)$ & 210.65 & 217.49 & 229.72 & 386.05 & 403.50 & 409.86 & 370.85 & 390.07 & 400.15 \\
$T_{\max }\left({ }^{\circ} \mathrm{C}\right)$ & 314.94 & 329.05 & 336.20 & 435.70 & 459.80 & 465.91 & 430.50 & 450.46 & 470.50 \\
$T_{f}\left({ }^{\circ} \mathrm{C}\right)$ & 486.63 & 502.36 & 536.29 & 469.05 & 495.86 & 523.45 & 489.50 & 540.96 & 560.00 \\
Total Weight Loss, $\%$ & 61.83 & 60.13 & 53.45 & 98.63 & 93.50 & 91.32 & 77.94 & 74.77 & 73.56 \\
\hline
\end{tabular}

Figure 2 showed that thermal decomposition of SM and PET differ from each other. Sheep manure (SM) was mainly composed by hemicellulose, cellulose, lignin, and some other organic materials. In contrast, PET was a long linear polymer with a high degree of crystallinity and low branching [12]. SM degraded at a lower temperature and in a broader decomposition range compared to PET, which was consistent with previous studies [29,30]. The DTG curve for SM can be divided into three main stages. In the first stage (up to $200{ }^{\circ} \mathrm{C}$ ), there occurred evaporation of free moisture, primary decomposition of unstable biopolymers, followed by devolatilization due to secondary reactions such as cracking and repolymerization [31]. In the second stage $\left(200-450{ }^{\circ} \mathrm{C}\right)$ the main weight loss was observed, where the active pyrolysis occurred by devolatilization, cellulose, hemicellulose and partial lignin degradation, which are the major components in the waste material. The third stage $\left(600-800^{\circ} \mathrm{C}\right)$ corresponded to the continuous devolatilization with lignin degradation and char formation. Similar results were reported for biomass pyrolysis in previous studies [21,26]. Single peaks observed in the temperature range of $400-500{ }^{\circ} \mathrm{C}$ in 
DTG of PET suggested the overall single step degradation. Degradation characteristics of PET were found to be similar for polymer degradations such as LDPE and HDPE [32,33]. SM showed typical biomass characteristics, and decomposed at lower temperatures than PET. This was attributed to the structure of PET, which is less complicated compared to that of biomass. The heating rate is an important factor during pyrolysis. As can be seen from Table 2, the maximum temperature shifted towards higher values by increasing the heating rate without altering thermal decomposition $[23,34,35]$.

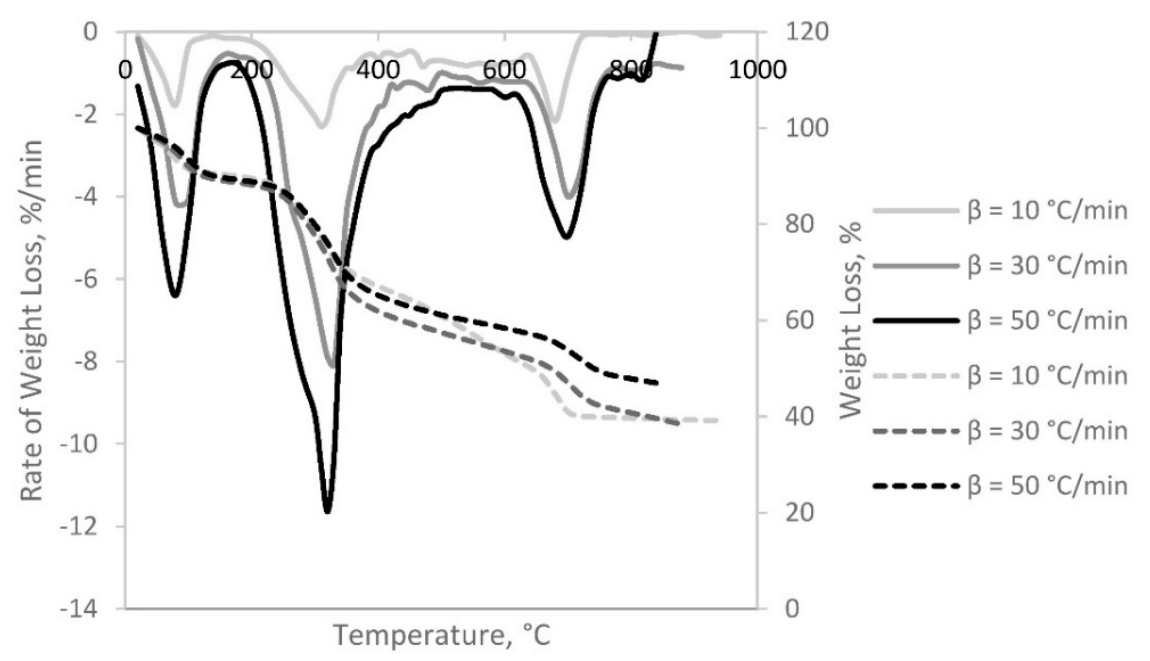

(a)

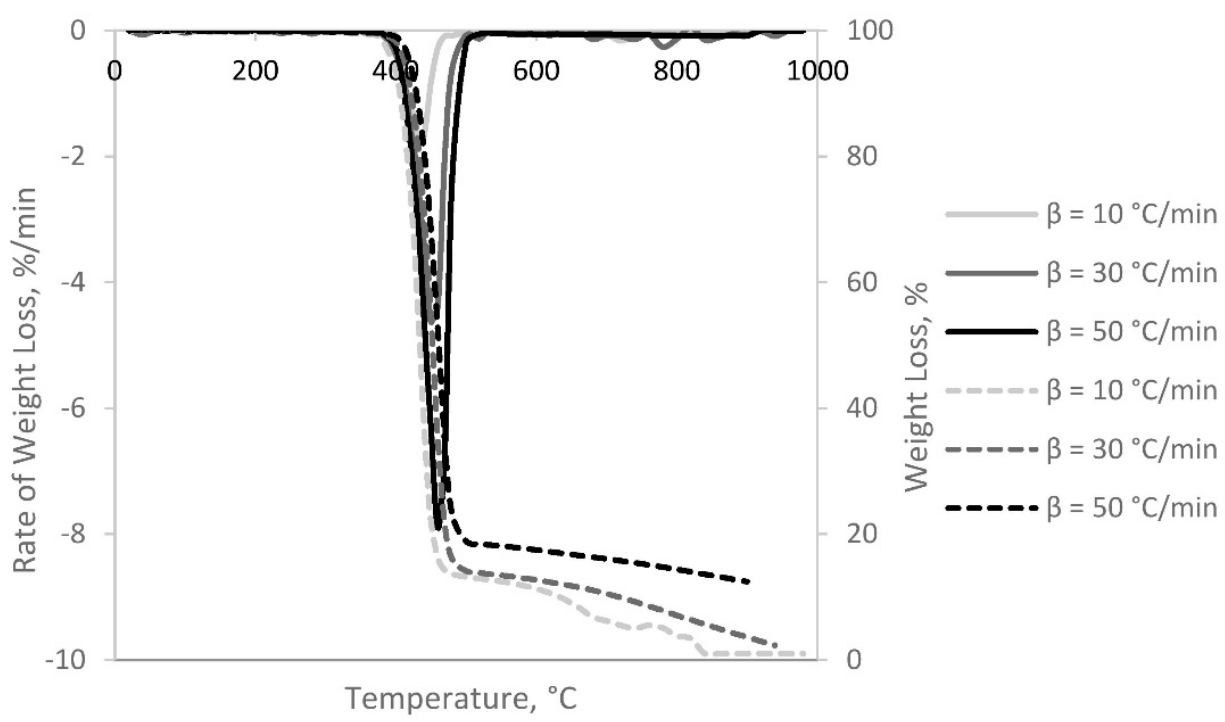

(b)

Figure 2. TG and DTG Graphs of (a) SM and (b) PET at different heating rates.

Synergetic effects of the manure and PET co-pyrolysis was investigated by comparing the theoretical and experimental thermogravimetric analysis results. The theoretical values of the blends was calculated by the weighted-average sum of the individual sample's TGA experiment values. PET blending with SM increased the rate of volatile evolution during manure decomposition, and lowered the peak corresponding to pyrolysis compared to the weighted DTG.

Theoretical data and experimental results of co-pyrolysis showed that positive synergy occurred between the SM and PET. As seen from Figure 3, weight loss during co-pyrolysis was greater than the theoretical mean values, which are calculated from SM and PET. The 
apparent activation energy of co-pyrolysis lowered the activation energy compared to PET pyrolysis, suggesting a reduction in energy consumption for pyrolysis [36].

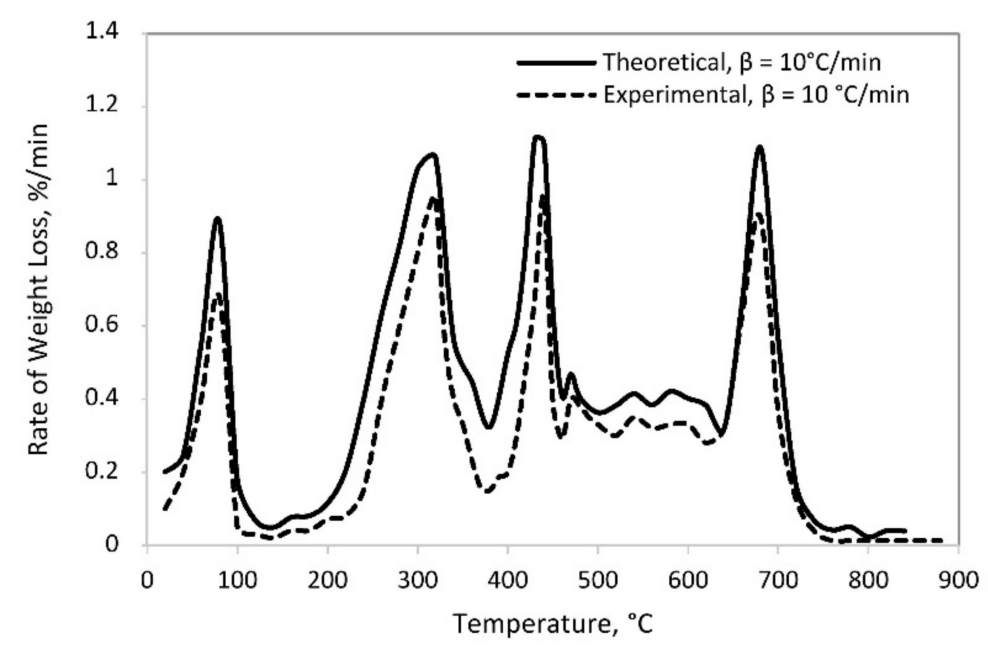

(a)

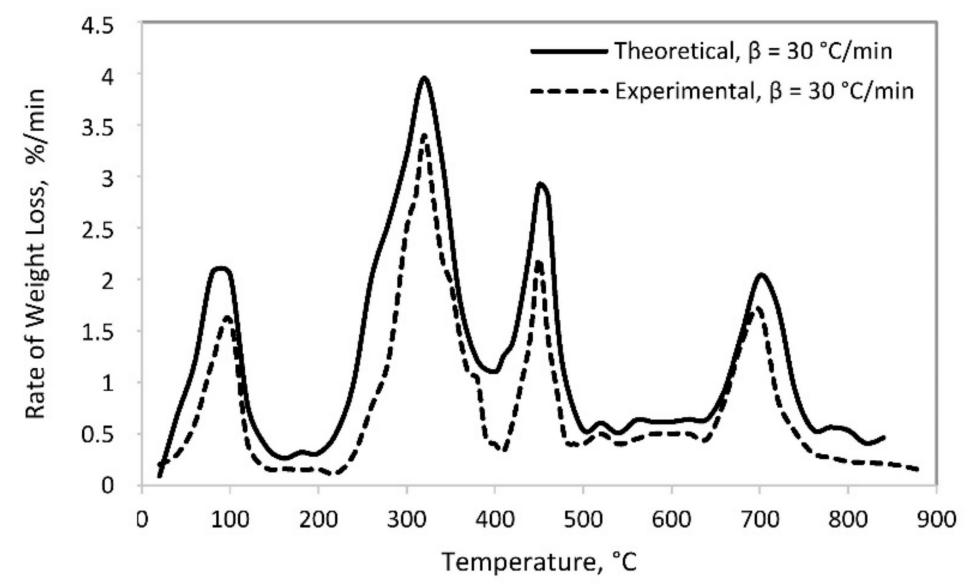

(b)

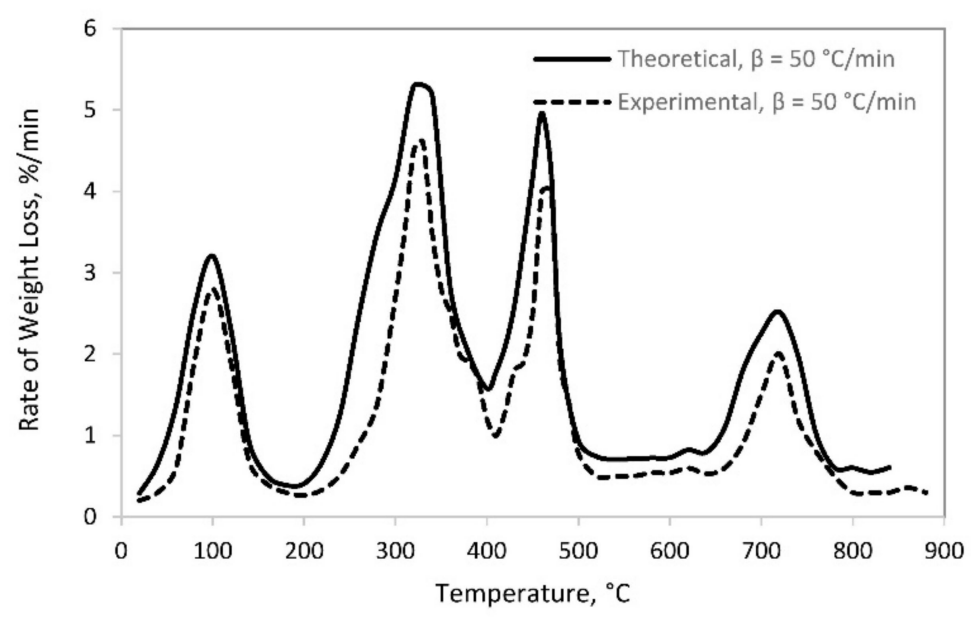

(c)

Figure 3. Comparison of theoretical and experimental data of SM/PET blend (a) $\beta=10 \mathrm{C}^{\circ} / \mathrm{min}$, (b) $\beta=30^{\circ} \mathrm{C} / \mathrm{min},(\mathbf{c}) \beta=50^{\circ} \mathrm{C} / \mathrm{min}$. 


\subsection{Kinetic Analysis}

Kinetic study of biomass serves better understanding of reaction mechanisms. Kinetic parameters are used to predict reaction behaviors during thermal degradation of materials [37]. The Ozawa-Flynn-Wall (OFW) model was used for fitting the DTGs of pyrolysis of SM and PET (Figure 4). Activation energy is defined as the minimum amount of energy required to initiate the reaction. Activation energy corresponds to reaction kinetics and reaction mechanisms of pyrolysis. The higher the activation energy, the slower the reaction [38]. The activation energies calculated are shown in Table 3. The correlation coefficient were higher than 0.98 , which implied good correlation with experimental data.

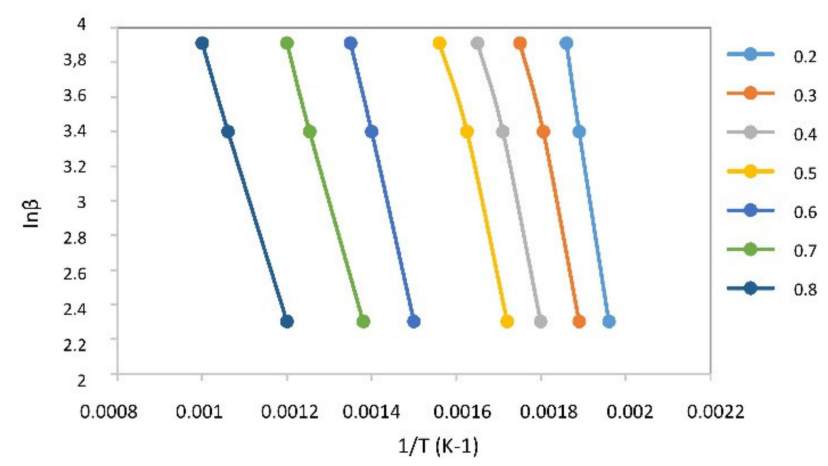

(a)

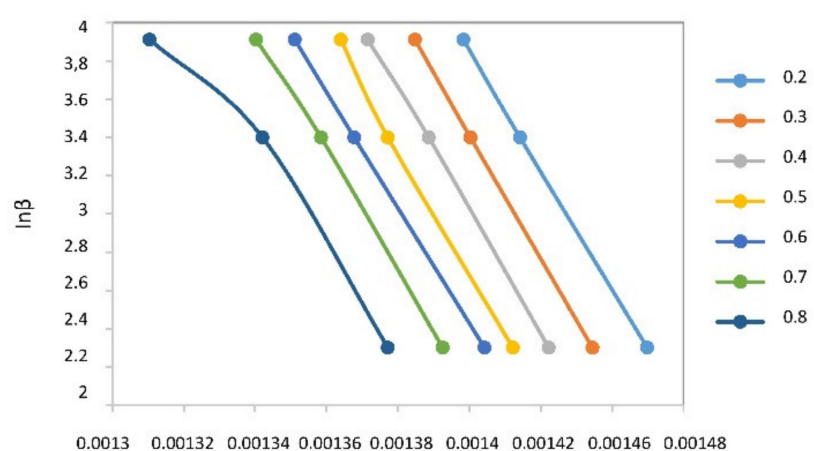

$1 / \mathrm{T}(\mathrm{K}-1)$

(b)

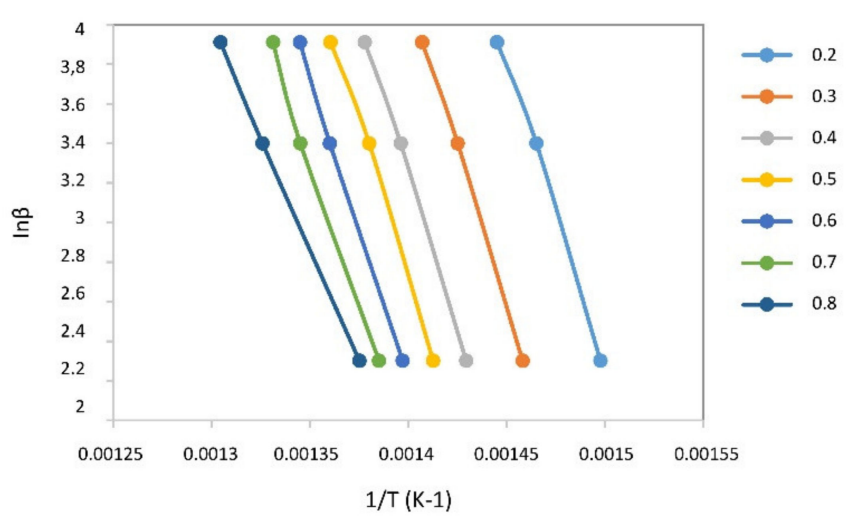

(c)

Figure 4. Linear correlation for determining activation energy of SM, PET, and their blend calculated by FWO (a), (b), (c), respectively. 
Table 3. Kinetic parameters for the pyrolysis of cattle manure, recycled polyester and their blend.

\begin{tabular}{|c|c|c|c|c|c|c|}
\hline$\alpha$ & $\begin{array}{c}E_{a} \\
(\mathrm{~kJ} / \mathrm{mol})\end{array}$ & $\begin{array}{c}A \\
\left(\mathrm{~s}^{-1}\right)\end{array}$ & $R^{2}$ & $\begin{array}{c}\Delta H \\
(\mathrm{~kJ} / \mathrm{mol})\end{array}$ & $\begin{array}{c}\Delta G \\
(\mathrm{~kJ} / \mathrm{mol})\end{array}$ & $\begin{array}{c}\Delta S \\
(\mathrm{~J} / \mathrm{mol} \mathrm{K})\end{array}$ \\
\hline \multicolumn{7}{|c|}{ SM } \\
\hline 0.2 & 126.64 & $1.30 \times 10^{+09}$ & 0.9915 & 121.75 & 171.38 & -84.39 \\
\hline 0.3 & 91.83 & $7.63 \times 10^{+05}$ & 0.9957 & 86.94 & 172.95 & -146.26 \\
\hline 0.4 & 86.29 & $2.31 \times 10^{+05}$ & 0.9932 & 81.40 & 173.26 & -156.19 \\
\hline 0.5 & 80.37 & $6.41 \times 10^{+04}$ & 0.9990 & 75.48 & 173.60 & -166.86 \\
\hline 0.6 & 85.08 & $1.78 \times 10^{+05}$ & 0.9965 & 80.19 & 173.32 & -158.36 \\
\hline 0.7 & 70.30 & $7.15 \times 10^{+03}$ & 0.9955 & 65.41 & 174.26 & -185.09 \\
\hline 0.8 & 63.39 & $1.57 \times 10^{+03}$ & 0.9941 & 58.50 & 174.76 & -197.70 \\
\hline Average & 86.27 & & & 81.38 & 173.36 & \\
\hline \multicolumn{7}{|c|}{ PET } \\
\hline 0.2 & 246.50 & $1.44 \times 10^{+16}$ & 0.9990 & 240.61 & 205.95 & 48.90 \\
\hline 0.3 & 255.84 & $7.28 \times 10^{+16}$ & 1.0000 & 249.94 & 205.73 & 62.37 \\
\hline 0.4 & 251.89 & $3.67 \times 10^{+16}$ & 0.9975 & 246.00 & 205.82 & 56.68 \\
\hline 0.5 & 260.83 & $1.73 \times 10^{+17}$ & 0.9978 & 254.94 & 205.62 & 69.58 \\
\hline 0.6 & 239.19 & $4.04 \times 10^{+15}$ & 1.0000 & 233.30 & 206.13 & 38.34 \\
\hline 0.7 & 244.90 & $1.09 \times 10^{+16}$ & 0.9947 & 239.01 & 205.99 & 46.58 \\
\hline 0.8 & 191.53 & $9.94 \times 10^{+11}$ & 0.9752 & 185.64 & 207.44 & -30.75 \\
\hline Average & 241.53 & & & 235.63 & 206.09 & \\
\hline \multicolumn{7}{|c|}{ Blend (1:1 wt $\%)$} \\
\hline 0.2 & 244.14 & $2.47 \times 10^{+16}$ & 0.9980 & 238.37 & 201.21 & 53.57 \\
\hline 0.3 & 250.40 & $7.50 \times 10^{+16}$ & 0.9987 & 244.63 & 201.07 & 62.81 \\
\hline 0.4 & 248.42 & $5.28 \times 10^{+16}$ & 0.9985 & 242.66 & 201.11 & 59.89 \\
\hline 0.5 & 245.89 & $3.37 \times 10^{+16}$ & 0.9977 & 240.12 & 201.17 & 56.15 \\
\hline 0.6 & 241.63 & $1.58 \times 10^{+16}$ & 0.9965 & 235.86 & 201.27 & 49.86 \\
\hline 0.7 & 231.66 & $2.69 \times 10^{+15}$ & 0.9973 & 225.89 & 201.52 & 35.15 \\
\hline 0.8 & 179.44 & $2.44 \times 10^{+11}$ & 0.9901 & 173.67 & 202.99 & -42.26 \\
\hline Average & 234.51 & & & 228.74 & 201.48 & \\
\hline
\end{tabular}

The average $E_{a}$ values of SM, PET and blend estimated with the FWO method were: $86.27 \mathrm{~kJ} / \mathrm{mol}, 241.53 \mathrm{~kJ} / \mathrm{mol}$, and $234.51 \mathrm{~kJ} / \mathrm{mol}$, respectively. As can be seen from Table 3, activation energies in the conversion degree range of $0.2-0.8$, reduced with co-pyrolysis. Reduction activation energy was reported during co-pyrolysis of biomass with plastic waste [36-39]. Co-pyrolysis resulted in a gradual decrease in average activation energy. This may be due to activation and decomposition of biomass components such as cellulose, hemicellulose, lignin, extractives and other components [40]. Reduction in activation energy depicts easier thermal conversion [41]. The activation energy of PET was found to be greater than SM due to structural differences between biomass and plastic waste [37]. Blending lowered the required activation energy to initiate the reaction.

In calculation of the pre-exponential factors, a $10{ }^{\circ} \mathrm{C} / \mathrm{min}$ heating rate was used. The pre-exponential factors calculated using the FWO model varied from $\mathrm{E}+03 \mathrm{~s}^{-1}$ to $\mathrm{E}+16 \mathrm{~s}^{-1}$, indicating the occurrence of complex reactions during thermal processing. The pre-exponential factor $(A \geq 109)$ implied a simple complex with high reactivity [41]. The thermodynamic parameters were given in Table 3. The change in enthalpy $(\Delta H)$ indicated if the reaction process was endothermic or exothermic. $\Delta H$ values in all conversion degrees were positive, indicating occurrence of endothermic reactions during pyrolysis processes. The difference between activation energy and enthalpy were within the range of $4 \mathrm{kj} / \mathrm{mol}-6 \mathrm{kj} / \mathrm{mol}$, which implied product formation with a small amount of energy [42]. The results are in agreement with previous studies $[43,44]$.

Entropy change $(\Delta S)$ determines the reactivity of reaction systems. The negative value of entropy during SM degradation implied that the degree of disorder of the products is much lower than the SM. The higher value of entropy means higher reactivity and 
shorter reaction times during PET decomposition [45,46]. The blend has shown variations in entropy, and has conducted different behavior than the feedstock. Gibbs free energy $(\Delta G)$ analysis indicated the amount of energy available from the material. The average values of $\Delta G$ were found to be $173.36 \mathrm{~kJ} / \mathrm{mol}, 206.09 \mathrm{~kJ} / \mathrm{mol}$, and $228.74 \mathrm{~kJ} / \mathrm{mol}$ for SM, $\mathrm{PET}$, and their blend, respectively. The calculated $\Delta G$ values have shown that co-pyrolysis of the SM-PET blend has a considerable bioenergy potential.

\section{Conclusions}

In this study, co-pyrolysis of sheep manure and recycled polyethylene terephthalate was examined in order to understand the kinetics and synergetic effects. TGA analysis demonstrated the existence of synergistic effects during co-pyrolysis. The apparent activation energies of SM, PET, and their blend were calculated by the FWO method as 86.27, 241.53 , and $234.51 \mathrm{~kJ} / \mathrm{mol}$, respectively. Higher Gibbs free energy analysis of the blend implied the amount of available green energy from the waste materials. Co-pyrolysis can serve as an alternative waste management method that has significant impact on waste utilization and energy production.

Funding: This research received no external funding.

Conflicts of Interest: The author declares no conflict of interest.

\section{References}

1. CO2 Emissions from Fuel Combustion: Overview. Statistics Report. International Energy Agency. 2020. Available online: https://www.iea.org/reports/co2-emissions-from-fuel-combustion-overview (accessed on 29 April 2021).

2. Bioenergy Annual Report. International Energy Agency. 2020. Available online: https://www.iea.org/reports/bioenergy-powergeneration (accessed on 15 June 2021).

3. World Energy Outlook, Sustainable Development Scenario. 2020. Available online: https://iea.blob.core.windows.net/assets/ dd88335f-91ab-4dbd-8de7-d2dc4fee90e0/WEM_Documentation_WEO2020.pdf (accessed on 15 June 2021).

4. Burra, K.G.; Gupta, A.K. Kinetics of synergistic effects in co-pyrolysis of biomass with plastic wastes. Appl. Energy 2018, 220, 408-418. [CrossRef]

5. Graham, J.P.; Nachman, K.E. Managing Waste from confined animal feeding operations in the United States: The need for sanitary reform. J. Water Health 2010, 8, 646-670. [CrossRef] [PubMed]

6. Carlin, N.; Annamalai, K.; Sweeten, J.; Mukhtar, S. Thermo-Chemical Conversion Analysis on Dairy Manure-Based Biomass through Direct Combustion. Int. J. Green Energy 2007, 4, 133-159. [CrossRef]

7. Plastics-the Facts 2020, Plastics Europe, Association of Plastics Manufacturers. Available online: https://www.plasticseurope. $\mathrm{org} / \mathrm{en} /$ resources/publications/4312-plastics-facts-2020 (accessed on 15 June 2021).

8. Buekens, A. Introduction to Feedstock Recycling of Plastics; John Wiley \& Sons Ltd.: Hoboken, NJ, USA, 2006; pp. 1-41.

9. Lazarevic, D.; Aoustin, E.; Buclet, N.; Brandt, N. Plastic waste management in the context of a European recycling society: Comparing results and uncertainties in a life cycle perspective. Resour. Conserv. Recycl. 2010, 55, 246-259. [CrossRef]

10. Kukreja, R. Advantages and disadvantages of recycling. Conserve Energy Future. 2009. Available online: https:/ /www.conserveenergy-future.com/advantages-and-disadvantages-of-recycling.php (accessed on 17 July 2021).

11. Das, P.; Tiwari, P. The effect of slow pyrolysis on the conversion of packaging waste plastics (PE and PP) into fuel. Waste Manag. 2018, 79, 615-624. [CrossRef]

12. Sharuddin, S.D.A.; Abnisa, F.; Daud, W.M.A.W.; Aroua, M.K. A review on pyrolysis of plastic wastes. Energy Convers. Manag. 2016, 115, 308-326. [CrossRef]

13. Xue, Y.; Kelkar, A.; Bai, X. Catalytic co-pyrolysis of biomass and polyethylene in a tandem micropyrolyzer. Fuel 2016, 166, 227-236. [CrossRef]

14. Oyedun, A.O.; Tee, C.Z.; Hanson, S.; Hui, C.W. Thermogravimetric analysis of the pyrolysis characteristics and kinetics of plastics and biomass blends. Fuel Process. Technol. 2014, 128, 471-481. [CrossRef]

15. Kiran, N.; Ekinci, E.; Snape, C.E. Recyling of plastic wastes via pyrolysis. Resour. Conserv. Recycl. 2000, 29, 273-283. [CrossRef]

16. Amenaghawon, A.N.; Anyalewechi, C.L.; Okieimen, C.O.; Kusuma, H.S. Biomass pyrolysis technologies for value-added products: a state-of-the-art review. Environ. Dev. Sustain. 2021. [CrossRef]

17. Lee, X.J.; Lee, L.Y.; Gan, S.; Thangalazhy-Gopakumar, S.; Ng, H.K. Biochar potential evaluation of palm oil wastes through slow pyrolysis: Thermochemical characterization and pyrolytic kinetic studies. Bioresour. Technol. 2017, 236, 155-163. [CrossRef] [PubMed]

18. Amutio, M.; Lopez, G.; Aguado, R.; Bilbao, J.; Olazar, M. Biomass oxidative flash pyrolysis: Autothermal operation, yields and product properties. Energy Fuels 2012, 26, 1353-1362. [CrossRef] 
19. Caballero, J.A.; Conesa, J.A.; Font, R.; Marcilla, A. Pyrolysis kinetics of almond shells and olive stones considering their organic fractions. J. Anal. Appl. Pyrol. 1997, 42, 159-175. [CrossRef]

20. Ahmaruzzaman, M.; Sharma, D.K. Coprocessing of petroleum vacuum residue with plastics, coal, and biomass and its synergistic effects. Energy Fuels 2007, 21, 891-897. [CrossRef]

21. Zhang, X.; Lei, H.; Zhu, L.; Zhu, X.; Qian, M.; Yadavalli, G.; Wu, J.; Chen, S. Thermal behavior and kinetic study for catalytic co-pyrolysis of biomass with plastics. Bioresour. Technol. 2016, 220, 233-238. [CrossRef]

22. Aboulkas, A.; El harfi, K.; El bouadili, A.; Nadifiyine, M.; Benchanaa, M.; Mokhlisse, A. Pyrolysis kinetics of olive residue/plastic mixtures by non-isothermal thermogravimetry. Fuel Process. Technol. 2009, 90, 722-728. [CrossRef]

23. Alam, M.; Bhavanam, A.; Jana, A.; Viroja, J.K.S.; Peela, N.P. Co-pyrolysis of bamboo sawdust and plastic: Synergistic effects and kinetics. Renew. Energy 2020, 149, 1133-1145. [CrossRef]

24. Uzoejinwa, B.B.; He, X.; Wang, S.; Abomohra, A.E.F.; Hu, Y.; Wang, Q. Co-pyrolysis of biomass and waste plastics as a thermochemical conversion technology for high-grade biofuel production: Recent progress and future directions elsewhere worldwide. Energy Convers. Manag. 2018, 163, 468-492. [CrossRef]

25. Cai, J.; Wang, Y.; Zhou, L.; Huang, Q. Thermogravimetric analysis and kinetics of coal/plastic blends during co-pyrolysis in nitrogen atmosphere. Fuel Process. Technol. 2008, 89, 21-27. [CrossRef]

26. Zhou, L.; Luo, T.; Huang, Q. Co-pyrolysis characteristics and kinetics of coal and plastic blends. Energy Convers. Manag. 2009, 50, 705-710. [CrossRef]

27. Flynn, J.H.; Wall, L.A. General treatment of the thermogravimetry of polymers. J. Res. Natl. Bur. Stand. 1966, 70, 487-523. [CrossRef] [PubMed]

28. Ozawa, T. A new method of analyzing thermogravimetric data. Bull. Chem. Soc. Jpn. 1965, 38, 1881-1886. [CrossRef]

29. Chen, G.; Yang, R.; Cheng, Z.; Yan, B.; Ma, W. Nitric oxide formation during corn straw/sewage sludge co-pyrolysis/gasification. J Clean. Prod. 2018, 197, 97-105. [CrossRef]

30. Kai, X.; Yang, T.; Shen, S.; Li, R. TG-FTIR-MS study of synergistic effects during co-pyrolysis of corn stalk and high-density polyethylene (HDPE). Energy Convers. Manag. 2019, 181, 202-213. [CrossRef]

31. Kan, T.; Strezov, V.; Evans, T.J. Lignocellulosic biomass pyrolysis: A review of product properties and effects of pyrolysis parameters. Renew. Sust. Energy Rev. 2016, 57, 1126-1140. [CrossRef]

32. Das, P.; Tiwari, P. Valorization of packaging plastic waste by slow pyrolysis. Resour. Conserv. Recycl. 2018, 128, 69-77. [CrossRef]

33. Yu, X.; Wang, S.; Zhang, J. Preparation of high adsorption performance activated carbon by pyrolysis of waste polyester. J. Mater. Sci. 2018, 53, 5458-5466. [CrossRef]

34. Chandrasekaran, A.; Ramachandran, S.; Subbiah, S. Determination of kinetic parameters in the pyrolysis operation and thermal behavior of Prosopis juliflora using thermogravimetric analysis. Bioresour. Technol. 2017, 223, 413-422. [CrossRef] [PubMed]

35. Samuelsson, L.N.; Babler, M.U.; Moriana, R. A single model-free rate expression describing both non-isothermal and isothermal pyrolysis of Norway Spruce. Fuel 2015, 161, 59-67. [CrossRef]

36. Akyürek, Z. Sustainable Valorization of Animal Manure and Recycled Polyester: Co-pyrolysis Synergy. Sustainability 2019, 11, 2280. [CrossRef]

37. Mishra, R.K.; Sahoo, A.; Mohanty, K. Pyrolysis kinetics and synergistic effect in co-pyrolysis of Samanea saman seeds and polyethylene terephthalate using thermogravimetric analyser. Bioresour. Technol. 2019, 289, 121608. [CrossRef]

38. Mishra, R.K.; Mohanty, K. Pyrolysis kinetics and thermal behavior of waste sawdust biomass using thermogravimetric analysis. Bioresour. Technol. 2018, 251, 63-74. [CrossRef] [PubMed]

39. Hu, Z.; Ma, X.; Li, L. The synergistic effect of co-pyrolysis of oil shale and microalgae to produce syngas. J. Energy Inst. 2016, 89, 447-455. [CrossRef]

40. Xu, X.; Pan, R.; Chen, R. Combustion Characteristics, Kinetics, and Thermodynamics of Pine Wood through Thermogravimetric Analysis. Appl. Biochem. Biotechnol. 2021, 193, 1427-1446. [CrossRef] [PubMed]

41. Yuan, X.; He, T.; Cao, H.; Yuan, Q. Cattle manure pyrolysis process: Kinetic and thermodynamic analysis with isoconversional methods. Renew. Energy 2017, 107, 489-496. [CrossRef]

42. Mortari, D.A.; Torquato, L.D.M.; Crespi, M.S.; Crnkovic, P.M. Co-firing of blends of sugarcane bagasse and coal. J. Therm. Anal. Calorim. 2018, 132, 1333-1345. [CrossRef]

43. Khan, A.S.; Man, Z.; Bustam, M.A.; Kait, C.F.; Ullah, Z.; Nasrullah, A.; Khan, M.I.; Gonfa, G.; Ahmad, P.; Muhammad, N. Kinetics and thermodynamic parameters of ionic liquid pretreated rubber wood biomass. J. Mol. Liq. 2016, 223, 754-762. [CrossRef]

44. Mehmood, M.A.; Ye, G.; Luo, H.; Liu, C.; Malik, S.; Afzal, I.; Xu, J.; Ahmad, M.S. Pyrolysis and kinetic analyses of Camel grass (Cymbopogon schoenanthus) for bioenergy. Bioresour. Technol. 2017, 228, 18-24. [CrossRef]

45. Turmanova, S.C.; Genieva, S.; Dimitrova, A.; Vlaev, L. Non-isothermal degradation kinetics of filled with rise husk ash polypropene composites. Express Polym. Lett. 2008, 2, 133-146. [CrossRef]

46. Ruvolo-Filho, A.; Curti, P.S. Chemical kinetic model and thermodynamic compensation effect of alkaline hydrolysis of waste poly(ethylene terepftalate) in nonaqueous ethylene glycol solution. Ind. Eng. Chem. Res. 2006, 45, 7985-7996. [CrossRef] 